\title{
The Interplay between Atmospheric Conditions and Grape Berry Quality Parameters in Portugal
}

\author{
Cátia Costa ${ }^{1,2, *}$, António Graça ${ }^{1}\left(\mathbb{D}\right.$, Natacha Fontes ${ }^{1}$, Marta Teixeira ${ }^{1}$, Hernâni Gerós ${ }^{2,3,4} \oplus$ and \\ João A. Santos 4 (iD) \\ 1 Sogrape Vinhos, S.A., Rua 5 de Outubro 4527, 4430-852 Avintes, Portugal; antonio.graca@sogrape.pt (A.G.); \\ Natacha.fontes@sogrape.pt (N.F.); marta.teixeira@sogrape.pt (M.T.) \\ 2 Centre of Molecular and Environmental Biology (CBMA), Department of Biology, University of Minho, \\ 4710-057 Braga, Portugal; geros@bio.uminho.pt \\ 3 Centre of Biological Engineering (CEB), Department of Biological Engineering, University of Minho, \\ 4710-057 Braga, Portugal \\ 4 Centre for the Research and Technology of Agro-environmental Sciences, CITAB, University of \\ Trás-os-Montes e Alto Douro, UTAD, 5001-801 Vila Real, Portugal; jsantos@utad.pt \\ * Correspondence: catia-costa17@hotmail.com
}

Received: 18 June 2020; Accepted: 16 July 2020; Published: 18 July 2020

\begin{abstract}
The atmospheric conditions are a strong modulator of grape berry composition, but further research is required to better understand this relationship, which is particularly pertinent under the context of climate change. The present study assesses the relationship between interannual variability in atmospheric conditions (mean, maximum and minimum air temperatures and precipitation totals) on grape berry quality attributes in three main Portuguese wine regions-Douro, Dão and Alentejo-and targets two major varieties growing in Portugal (cv. Touriga Nacional and cv. Aragonez/Tempranillo). Berry weight, titratable acidity (TA), $\mathrm{pH}$, potential alcohol (PA), anthocyanins and total phenols index (TPI) data, collected two to three weeks after the end of the veraison until technological maturity, since 1999 in Douro, 2004 in Alentejo and 2008 in Dão, were selected. Meteorological data were obtained from both automatic weather stations and a climatic database defined at a very-high-resolution grid $(<1 \mathrm{~km})$ (PTHRES). The influence of daily mean, maximum and minimum air temperatures (November-October) and precipitation totals (April to June and July to September) on the above-mentioned berry quality parameters were first explored to identify the months/periods more influential to grape berry composition. Different statistical approaches were subsequently carried out to explore in greater detail these relationships. At technological maturity, temperature was negatively correlated to berry weight, titratable acidity, anthocyanins and TPI, but was positively correlated to $\mathrm{pH}$ and potential alcohol. Moreover, lowest levels of berry weight and TA (and highest levels of $\mathrm{pH}$ ) were more frequent in warmer regions, while the opposite was seen in the cooler regions. PA, TPI and anthocyanins at maturity did not show a clear trend across regions. In addition, the maturation parameters of each site were grouped into two clusters-years where the maturation parameter is higher (cluster 1 ) and years where it is lower (cluster 2)-and significant differences in monthly mean temperatures between clusters were found. Overall, temperatures at veraison and maturation periods (June-August) were more influential in determining grape berry composition at harvest. The influence of precipitation was dependent on location and variety. The results also suggested that berry composition in Alentejo is more sensitive to atmospheric variability, while Aragonez seems more resilient than Touriga Nacional. These outcomes are based on a systematized and unprecedentedly large grape berry quality database in Portugal and provided the grounds for the development of grape quality forecast models, either to be used operationally in each vintage or for assessing potential modifications in berry composition in response to changing climates.
\end{abstract}


Keywords: climate variability; climate change; viticulture; berry quality; grape maturation; anthocyanins; phenolic compounds; Touriga Nacional; Aragonez; Portugal

\section{Introduction}

Grapevines are one of the most economically important fruit species worldwide. The current world vineyard area is approximately 7.4 million ha and Portugal ranked fifth and eleventh as a wine producer in Europe and worldwide, respectively [1]. The viticultural and winemaking sector heavily relies on the ability to produce high-quality wines, which are in turn strongly dependent on grape berry chemical components and their concentration at harvest [2]. Although the suitability of a region for grapevine cultivation is largely controlled by growing season mean temperature that should range between 12 and $22^{\circ} \mathrm{C}$, other atmosphere-driven conditions, such as growing season length, radiation levels, winter minimum temperatures, spring and fall frosts or soil water balance, among others, are also important limiting factors [3]. Air temperature plays a central role in determining grapevine phenology [4], influencing the onset of phenological stages like budbreak, flowering and veraison and the phenophase intervals [5,6]. Temperature also affects grapevine yield [7], wine production [8] and quality [9]. Relatively constant and moderate temperatures during ripening favour the biochemical processes of colour, flavour and aroma development in grape berries [10]. For rainfed grapevines, the water balance is mainly determined by precipitation, atmospheric humidity and soil water holding capacity [10]. The amount of annual precipitation and its seasonal distribution are also crucial to the evolution of the plant water status, with subsequent effects on berry quality [10]. Moreover, under extremely dry atmospheric conditions, stomata can close to preserve moisture, ceasing photosynthesis [11]. Nevertheless, some reported effects of water stress on grape berry quality attributes are contradictory, being strongly dependent on the local conditions, on the degree of water stress and on the period in which it occurred.

The acid versus sugar balance is fundamental to build grape flavour, which ultimately determines the wine quality. Grape juice with low acidity often results in unstable musts and wines that are more susceptible to organoleptic degradation (e.g., due to oxidative and microbiological spoilage [12]), while excessive berry acidity is commonly undesirable for the production of high-quality wines. The titratable acidity levels are frequently lower in warmer years than in cooler ones [13]. It was suggested that some of the strongest and most consistent negative links between titratable acidity and temperature are related to maximum temperatures [14]. In general, respiration of tartaric and malic acids, particularly malic acid, increases with increasing temperatures, thus leading to a drop in titratable acidity and increased $\mathrm{pH}[15,16]$. Total acidity also drops due to the dilution of acids caused by increased berry size, but in semi-arid regions, total acidity values are significantly higher under irrigation than in non-irrigated conditions [17], hinting at the need of a minimum of water availability for balance in berry composition to be achieved. Furthermore, higher levels of malic acid measured under those conditions of irrigation may be associated with greater synthesis during the growth period [17]. Overall, titratable acidity at maturity is preserved with moderate precipitation and/or irrigation [14], which can be explained by a combined effect, of enhanced vegetative growth prior to maturity with greater moisture availability and by the lowering of air temperature often associated with rainy weather.

High temperatures promote sugar accumulation and thus higher potential alcohol levels $[18,19]$. Previous studies showed that total soluble solids accumulation are greater at higher temperatures $\left(30^{\circ} \mathrm{C}\right)$ than lower temperatures $\left(20^{\circ} \mathrm{C}\right)$ at veraison and a few days after $[20,21]$. During the growing season, the highest sugar content is frequently associated with drier years, while the lowest is related to rainier years [13]. It has been shown that water limitation affects plant hormonal equilibrium directing sugar accumulation in grape berries. Furthermore, in irrigated conditions, total soluble solids 
concentration can decrease due to the dilution caused by greater berry size [17], but enhanced sugar accumulation associated with higher photosynthetic activity also occurs under irrigation [22].

Although the mechanisms of phenolic biosynthesis at high temperatures are still poorly understood, the optimum temperature for phenolic accumulation is nearly $25^{\circ} \mathrm{C}$, while above or below this level accumulation tends to fall significantly [20]. The effect of temperature on grape berry anthocyanins content has been studied for different varieties and regions $[13,14,23,24]$. For instance, mature berries from Cabernet Sauvignon, Shiraz and Chardonnay varieties cultivated in cooler sites accumulate higher levels of anthocyanins than those from warmer climates [14]. High temperatures can reduce anthocyanins accumulation through either the impairment of its synthesis or the acceleration of its degradation [25]. In the berry skin of Darkridge (Vitis vinifera L. $\times$ Vitis labrusca L.), two enzymes of the anthocyanins biosynthetic pathway were favoured by cool night temperatures [21]. In water stress conditions, phenolic compounds, including anthocyanins, are concentrated due to berry size reduction. In addition, the biosynthesis of each phenolic compound is differently affected by the severity of the water deficit and the period when it occurs [26]. Water deficits during veraison and maturation increase anthocyanin [26-28], proanthocyanin and flavonol biosynthesis [26], while early in the growing season high water availability is beneficial for anthocyanins content, as it promotes vegetative growth and, consequently, berry development and composition at later stages [29]. However, other reports show that high moisture availability late in the growing season may reduce anthocyanins content [30].

Previous studies already demonstrated the role of some climatic variables in grape berry quality parameters [7,13,14,31,32], some of them using long-term historical data for a few variables [7]. To our knowledge, this is the only study that uses a long-time series of biochemical data in field conditions, for many berry quality aspects (berry weight, titratable acidity, $\mathrm{pH}$, potential alcohol, anthocyanins and TPI): maximum of 19 years for Douro region (1999-2017) and a minimum of six years for Alentejo region (2012-2017). Moreover, this study is unprecedented in Portugal, being the first to assess the climate-berry quality relationships using several grape berry quality parameters and over such a long time period.

Portuguese wine production is characterized by a strong interannual variability, which is a feature of Mediterranean climates, with adverse consequences for wine business [33]. Therefore, it is of great interest for the wine industry to understand the role of atmospheric variability on grape berry composition to develop and implement optimized agronomic/oenological strategies, such as stress mitigation agronomic practices while reducing water, fertilizers and pesticides usage. The identification of cause-effect relationships will set the grounds for the development of predictive models of grapevine quality and decision support tools that can be used either to monitor grapevine development, in the short-term, or to assess the potential impacts of climate change, in the long-term [34].

Hence, the present study aims to determine the responses of some key berry attributes to atmospheric variability, namely berry weight, titratable acidity (TA), $\mathrm{pH}$, potential alcohol (PA), anthocyanins and total phenols index (TPI). The study was carried out for three Portuguese wine regions (Douro, Dão and Alentejo) and two major grapevine varieties: cv. Touriga Nacional (TON, PRT52206) and cv. Aragonez (ARA, PRT52603, International synonym Tempranillo). A large and systematized database of both berry quality parameters and climate data in Portugal enabled an unprecedented comprehensive analysis of the interplay between climate and grape berry quality under the Portuguese Mediterranean-type conditions.

\section{Materials and Methods}

\subsection{Maturation Database}

In the present study, the maturation data were provided by Sogrape Vinhos S.A. (SV) and collected annually in the vineyards of SV and its supplier grape farmers. Data for three different Portuguese winemaking regions were used herein: Douro, Dão and Alentejo (Figure 1). Since these three regions have different terroirs and, mainly, are subject to different climatic conditions (their climatic 
characterization can be found in Section 3.1), they were selected to study the dynamics of grape berry quality parameters. These regions also provided longer and more consistent datasets of quality parameters. Vine blocks of two native varieties with strong national importance-cv. Touriga Nacional and cv. Aragonez-were chosen in Douro, Dão and Alentejo regions to study the dynamics of berry weight, titratable acidity, $\mathrm{pH}$, potential alcohol, total phenols index and anthocyanins at maturity. The blocks of each variety are composed of different genotypes, using in some cases single-clone on other mixed-clone plantations. Plant ages were also widely varied, from 5 to more than 30 years and naturally, increased along the observed time period. In each year, most analyses were performed weekly, two to three weeks after the end of veraison until harvest. All the data were compiled into a digital database and validation of wet chemical data was performed in the laboratory facilities of SV. Data quality checking was also regularly undertaken.

In the regions mentioned above, four vineyards were selected to be studied in this work (Table 1), and within those vineyards, a vine block (area specified in Table 1) was selected, based on two criteria: 1) blocks should be as close as possible to the local automatic weather station (AWS) and 2) maturity datasets should refer to ten or more years (for some vine blocks maturity data were available in the database for only a few years), except for the Alentejo region, where information for TON was only available for six years (Table 1). These choices aimed to maximize correlations between climate variables and grape berry quality parameters.

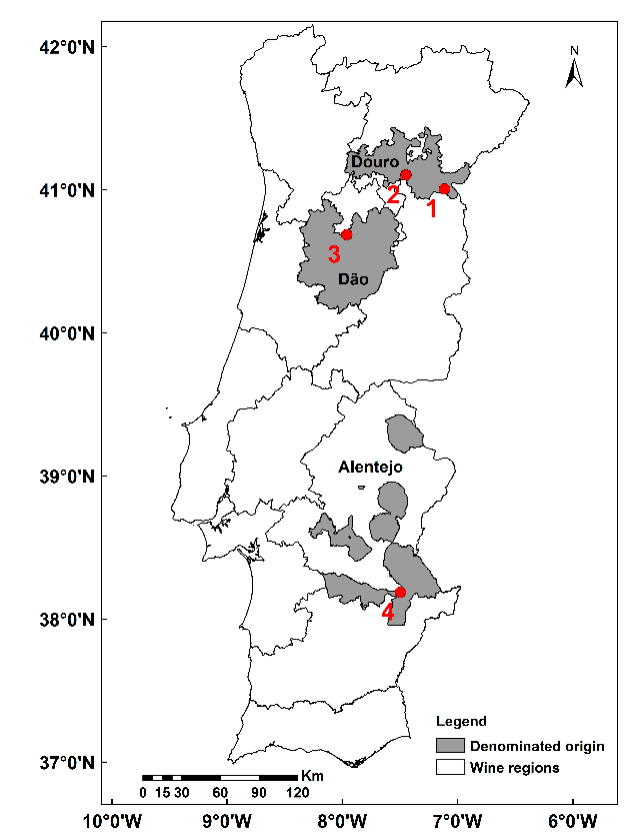

Figure 1. Winemaking regions where Sogrape Vinhos S.A. (SV) collected the data. The borders of the winemaking regions in Portugal are delimited as defined by the Portuguese Institute of Vine and Wine (IVV). Only Douro, Dão and Alentejo are selected in the present study, as longer periods of data are available for these three regions. The locations of the selected vineyards are also shown: 1-Douro-D, 2-Douro-C, 3-Dão and 4-Alentejo.

The bunch sampling method was adapted from previous reports [35]. Bunches were sampled manually, switching randomly between the side exposed to the sun and the shaded side of canopies. Berries were sampled randomly from the top to the tip of each bunch, placed in closed plastic bags and stored in refrigerated and insulated boxes during transport to the laboratory. Analyses of grape berry quality parameters commonly selected for maturation control—berry weight, titratable acidity, $\mathrm{pH}$, potential alcohol, total phenols index and anthocyanins-were performed up to $24 \mathrm{~h}$ after collection, and berries kept under refrigerated conditions. Collected berries were then divided into two sets of 200 berries each: one for analysis of berry weight, sugars and acids and another for phenolic 
compounds analysis. One set of berries was weighed and then crushed and decanted. The obtained grape was used to evaluate sugars, acidity and $\mathrm{pH}$. For sugar analysis, performed using refractometry, results were expressed in terms of potential alcohol percentage, considering $1 \%$ of potential alcohol as equivalent to $17 \mathrm{~g} / \mathrm{L}$ of total sugars. Titratable acidity was analysed by titration of the sample with $0.1 \mathrm{M} \mathrm{NaOH}$ solution and the results were expressed as $\mathrm{g}$ of tartaric acid equivalents per $\mathrm{L}$ of juice $(\mathrm{g} / \mathrm{L})$. $\mathrm{pH}$ was analysed with a digital potentiometer. Phenolic compound analysis was carried out with the second sample of 200 grape berries. The results were expressed in terms of extractable anthocyanins $(\mathrm{mg} / \mathrm{L})$ and total phenols index (TPI), following the methodology of Saint-Cricq and Vivas [36]. TPI is an indirect index of the total polyphenolic abundance in grapes and correlates with other phenolic compounds, such as phenolic acids and flavonoids, in addition to anthocyanins.

Table 1. Selected maturation data. Wine region, sub-region, vineyard designation, vine block area, variety (Touriga Nacional, TON, and Aragonez, ARA) and the period of the records are listed.

\begin{tabular}{cccccc}
\hline $\begin{array}{c}\text { Wine } \\
\text { Region }\end{array}$ & Sub-Region & $\begin{array}{c}\text { Vineyard } \\
\text { Designation }\end{array}$ & $\begin{array}{c}\text { Vine Block } \\
\left.\text { Area } \mathbf{( m}^{\mathbf{2}}\right)\end{array}$ & Variety & Years \\
\hline Alentejo & Vidigueira & Alentejo & 168000 & TON & $2012-2017$ \\
Alentejo & Vidigueira & Alentejo & 51000 & ARA & $2004-2017$ \\
Dão & Terras da Azurara & Dão & 16000 & TON & $2008-2017$ \\
Dão & Terras da Azurara & Dão & 23000 & ARA & $2008-2017$ \\
Douro & Cima Corgo & Douro-C & 42000 & TON & $2007-2017$ \\
Douro & Cima Corgo & Douro-C & 33000 & ARA & $2007-2017$ \\
Douro & Douro Superior & Douro-D & 187000 & TON & $1999-2017$ \\
Douro & Douro Superior & Douro-D & 19000 & ARA & $1999-2017$ \\
\hline
\end{tabular}

\subsection{Climate Data}

AWS located in or nearby the selected vineyard blocks (Table 1) provided daily average (TG), minimum (TN) and maximum (TX) air temperatures, as well as daily precipitation totals for the period of 2011-2017. As climatic data before 2011 are not available from the AWS, these variables were obtained from a gridded climatic database (PTHRES), available throughout Portugal on ca. $1 \mathrm{~km}$ spatial resolution and from 1950 onwards [37]. The nearest grid point to each vineyard was retrieved from PTHRES. As the determination coefficients of the linear regression models between PTHRES and AWS temperatures were very high ( $>90 \%$ for TN and $>98 \%$ for both TG and TX), linear equations were used to estimate TG, TN and TX before 2011. However, since the determination coefficients for precipitation were variable (51-92\%), a multiplicative method was used instead. Firstly, the climate-means of AWS and PTHRES monthly precipitation totals were calculated for each calendar month for the baseline period of 2011-2015. The corresponding monthly ratios were then interpolated to the daily timescale by a second-order polynomial fit. The daily precipitation totals before 2011 were then reconstructed by multiplying the corresponding ratio by PTHRES precipitation.

\subsection{Relationships of Grape Berry Quality Parameters with Climate Variables}

The potential influence of climatic variables on grape berry composition was examined at the berry maturation phase through correlation analyses. For this purpose, monthly means of TG, $\mathrm{TX}$ and TN and monthly precipitation totals during vine vegetative cycle (November-October) were selected. This exploratory correlation analysis allowed to identify the regions and plots more affected by interannual climate variability, thus deserving further research. The Pearson product-moment correlation coefficients were used. Even though the Spearman rank non-parametric correlations were also computed, the outcomes were very similar and thus will not be presented herein. These results highlight that the distributions of values are nearly Gaussian, therefore the application of non-parametric correlations is not necessary. The following terminology (Pearson's rule of thumb) will also be applied to the absolute value of the correlation coefficient: very weak $(<0.20)$, weak (from 0.20 to 0.39 ), moderate $(0.40-0.59)$, strong $(0.60-0.79)$ and very strong $(\geq 0.80)$ correlation [38]. For those sites, each grape berry 
quality parameter was divided into two clusters by the median: years where the maturation parameter was higher (cluster 1) and years where it was lower (cluster 2). We have chosen medians and not means, as the former non-parametric metric is much less sensitive to extreme values, thus being more robust from a statistical viewpoint. Furthermore, the split of the years based on, for example, quartiles, would result in very small samples that would threaten the representativeness of the clusters. The monthly mean temperatures of the two clusters for each grape quality parameter, region and variety studied, as well as the corresponding differences between cluster averages were calculated. For the largest monthly temperature differences found, daily temperature differences between clusters were calculated from June 1 to August 31. This analysis allowed for the identification of critical days/periods that may have contributed to the interannual variability of maturation parameters. An 11-day moving average was also applied in order to filter out erratic high-frequency oscillations and to isolate low frequency trends. The statistical significance of the differences was assessed by Student's $t$-test. For each grape quality parameter, cluster averages of each region were compared to each other by a one-way ANOVA analysis.

\section{Results}

\subsection{Climate Characterization of the Selected Sites}

Temperature and precipitation for each site and over the baseline period of 1991-2017 (period in which maturation data were available for study, however for the regions and vine blocks studied in this work, we only have data available since 1999 for Douro, 2004 for Alentejo and 2008 for Dão) were used (Table 2). The average growing season temperature (GST, April-October) [3], calculated over the baseline period, ranged from $18.1^{\circ} \mathrm{C}$ in Dão, or $18.2^{\circ} \mathrm{C}$ in Douro-C, to $20.5^{\circ} \mathrm{C}$ in Douro-D, or $21.1^{\circ} \mathrm{C}$ in Alentejo. The average (1991-2017) TG, TX and TN from June to August were also greater in Alentejo and Douro-D than in Douro-C and Dão. Furthermore, the average annual precipitation (1991-2017) showed that the Dão and Douro-C sites were the rainiest when compared to Alentejo and Douro-D (Table 2). Overall, warm Mediterranean-type conditions were found at the four sites, with Douro-D and Alentejo clearly warmer and drier than Dão and Douro-C. The Alentejo site is indeed close to the widely accepted upper thermal limit for viticultural suitability $\left(22^{\circ} \mathrm{C}\right)$, as previously mentioned. These conditions are in general agreement with several previous studies [39] and highlight that grapevines in Portugal are typically growing under moderate-to-severe water and heat stress conditions during the maturation period, though deficit irrigation systems are applied to avoid severe water stress [40]. Deficit irrigation is applied in order to enhance water management, owing to the low water resources available, as well as to promote berry quality [40]. Furthermore, the strong irregularity of the precipitation regime in Portugal frequently leads to severe or extreme drought conditions, driven by anomalies in the large-scale atmospheric flow [41,42], with major implications in viticulture [43]. Precipitation extremes are also an important threat [44], including hailstorms [45]. Temperature extremes, such as heatwaves, are also an important abiotic stress to take into account in the Portuguese conditions [46]. In addition, Portugal is expected to undergo significant changes in the grapevine growing conditions over the next decades, with warmer and drier climates, thus exacerbating these current limitations [39,47]. 
Table 2. Climatic characterization of the studied sites over the baseline period of 1991-2017. RR: annual mean precipitation (in mm); GST: growing season (April-October) mean temperature (in ${ }^{\circ} \mathrm{C}$ ); JJA TG/TX/TN: summertime mean (June-August) of the daily mean (TG), maximum (TX) and minimum (TN) temperature (in $\left.{ }^{\circ} \mathrm{C}\right)$.

\begin{tabular}{lccccc}
\hline Vineyard & GST $\left({ }^{\circ} \mathbf{C}\right)$ & JJA TG $\left({ }^{\circ} \mathbf{C}\right)$ & JJA TX $\left({ }^{\circ} \mathbf{C}\right)$ & JJA TN $\left({ }^{\circ} \mathbf{C}\right)$ & RR $(\mathbf{m m})$ \\
\hline 1. Douro-D & 20.5 & 24.4 & 31.8 & 16.2 & 563 \\
2. Douro-C & 18.2 & 21.9 & 29.0 & 14.0 & 681 \\
3. Dão & 18.1 & 21.3 & 29.5 & 12.9 & 992 \\
4. Alentejo & 21.1 & 24.2 & 33.1 & 15.5 & 637 \\
\hline
\end{tabular}

\subsection{Grape Berry Parameters versus Climate}

Regarding the grape berry quality parameters, their mean values for each studied vine block are displayed in Table 3.

Table 3. Characterization of the selected berry quality parameters. The values represent the average of each berry quality parameter. TON_Touriga Nacional; ARA—Aragonez; ${ }^{*} \mathrm{~g}$ of tartaric acid equivalents per $\mathrm{L}$ of juice.

\begin{tabular}{ccccccc}
\hline Vineyard & $\begin{array}{c}\text { Weight of } \\
\mathbf{1 0 0} \text { Berries } \\
\mathbf{( g )}\end{array}$ & $\begin{array}{c}\text { Titratable } \\
\text { Acidity } \\
\text { (g/L T.A.) }\end{array}$ & $\mathbf{p H}$ & $\begin{array}{c}\text { Potential } \\
\text { Alcohol } \\
\mathbf{( 1 7} \mathbf{g} / \mathbf{1} \%)\end{array}$ & TPI & $\begin{array}{c}\text { Anthocyanins } \\
\text { (mg/L) }\end{array}$ \\
\hline Douro-D (TON) & 135 & 4.35 & 3.85 & 12.70 & 40.80 & 282 \\
Douro-C (TON) & 189 & 5.80 & 3.55 & 12.80 & 41.25 & 301 \\
Dão (TON) & 150 & 5.05 & 3.72 & 12.00 & 40.95 & 426 \\
Alentejo (TON) & 135 & 4.10 & 3.86 & 13.50 & 55.50 & 419 \\
Douro-D (ARA) & 163 & 3.40 & 3.94 & 14.70 & 40.90 & 306 \\
Douro-C (ARA) & 222 & 4.40 & 3.77 & 14.40 & 39.80 & 369 \\
Dão (ARA) & 219 & 4.35 & 3.86 & 13.90 & 37.80 & 399 \\
Alentejo (ARA) & 167 & 3.70 & 4.06 & 14.75 & 53.30 & 503 \\
\hline
\end{tabular}

A first exploratory assessment revealed that only temperatures (TG, TX and TN) from June to August depict robust and statistically significant correlation coefficients with the berry quality parameters, which is coherent with the timing of the maturation period. Furthermore, for precipitation, better results were obtained when monthly precipitation totals were aggregated from April to June (flowering/fruiting phase) and from July to September (maturation phase). Hence, only these climatic variables were retained for subsequent analysis.

\subsubsection{Berry Weight}

The TON berry weight at maturity was negatively correlated with monthly temperatures of June, July and August in the four vineyards (Dão, Alentejo, Douro-C and Douro-D, Figure 2). Moderate to very strong negative correlations were observed with TG ( -0.50 to -0.83$)$ and TX ( -0.56 to -0.81$)$ in Alentejo, with August temperatures showing more influence on berry weight. Moreover, in Dão and Douro-C, moderate negative correlations were also found with TG and TX in July. In Douro-D, correlations were weak for all temperatures and months analysed. In general, in all sites, TN showed a much weaker influence on berry weight than TG and TX. Precipitation during the maturation period (July to September) increased berry weight, except in the Dão region, while a very strong positive correlation was observed in Alentejo (0.81). Similar to TON, the ARA berry weight tended to be negatively correlated with temperatures but, in general, correlations were weak to moderate (Figure 3). Berry weights in Alentejo and Douro-C were more correlated to June temperatures, while in Dão, July temperatures were more influential. In Douro-D, very weak correlations were observed between temperature and berry weight. A strong positive correlation between berry weight and precipitation during the maturation period (July to September) was only observed in Douro-C (0.79). 


\subsubsection{Titratable Acidity}

High temperatures during the maturation phase also negatively impacted the titratable acidity of TON berries. In Dão, the strength of the correlations increased steadily as the season progressed, peaking in August. TA was mainly affected by July temperatures in Alentejo, while correlations were moderate for all temperatures and months in Douro-C (Figure 2). Temperature negatively impacted TA levels of ARA berries at maturity, but mainly in Dão, with a growing trend throughout maturation (Figure 3). Generally, correlations between TA and precipitation were positive but weak (Figures 2 and 3). Negative correlations with precipitation were found in Alentejo and Douro-D. In these two regions grapevines are deficit-irrigated to avoid severe stress. Any precipitation occurring is not accounted for in the water allocation and may result in dissolution of all grape berry metabolites, including acids.

\subsection{3. $\mathrm{pH}$}

As expected, the correlations between temperature and berry $\mathrm{pH}$ were, in general, opposite to those found for TA, as $\mathrm{pH}$ tended to decrease with the increase of titratable acidity (Figures 2 and 3). Correlations of $\mathrm{pH}$ with temperatures during all months studied were relatively weak and inconsistent in Douro-D. For ARA, the temperature had significant positive impacts on $\mathrm{pH}$ levels only in Dão, with stronger correlations in August for all temperature variables. Negative correlations between berry $\mathrm{pH}$ and precipitation were found in Dão and Douro- $\mathrm{C}$ for both varieties. An unexpected positive correlation between $\mathrm{pH}$ of TON berries and precipitation in April to June period was observed in Alentejo (Figure 2).

\subsubsection{Potential Alcohol}

In Alentejo and Douro-C, potential alcohol levels of TON berries were positively correlated with temperature, with the effect of July TG and TX particularly apparent (Figure 2). Weak to moderate positive correlations were found between TN and PA in these regions. Nonetheless, in Dão and Douro-D, TN revealed very weak correlations. Only the temperature in June consistently affected alcohol levels positively in ARA grapes of Dão (Figure 3). For Dão, a strong negative correlation between precipitation and PA was observed for both varieties (Figures 2 and 3). In the remaining regions, precipitation had no clear effect on PA levels, possibly because of irrigation compensating for low precipitation.

\subsubsection{Total Phenols Index}

The results showed that temperature negatively impacted the total phenols index at maturity in TON berries from Alentejo. However, the opposite effect can be found in Douro-D (Figure 2). Correlations between temperature and TPI in ARA berries were weak to moderate and dependent on the region (Figure 3). Precipitation increased or reduced the phenols level, also depending on the region (Figures 2 and 3). The analysis of the impact of climatic variables on TPI is very complex, since the impact on different phenols can be different or even opposite.

\subsubsection{Anthocyanins}

The concentration of anthocyanins in both varieties was negatively associated with all temperatures. The correlations were particularly strong in Alentejo, where June temperatures (particularly TG and TX) depicted a great impact on the concentration of anthocyanins at maturity. Moderate correlations between minimum temperatures and anthocyanins at maturity were found for all regions. Correlations between precipitation and anthocyanins in TON berries were weak and depended on the region (Figure 2). Nevertheless, moderate positive and negative correlations were found between precipitation (from April to June) and anthocyanins in ARA berries (Figure 3). 


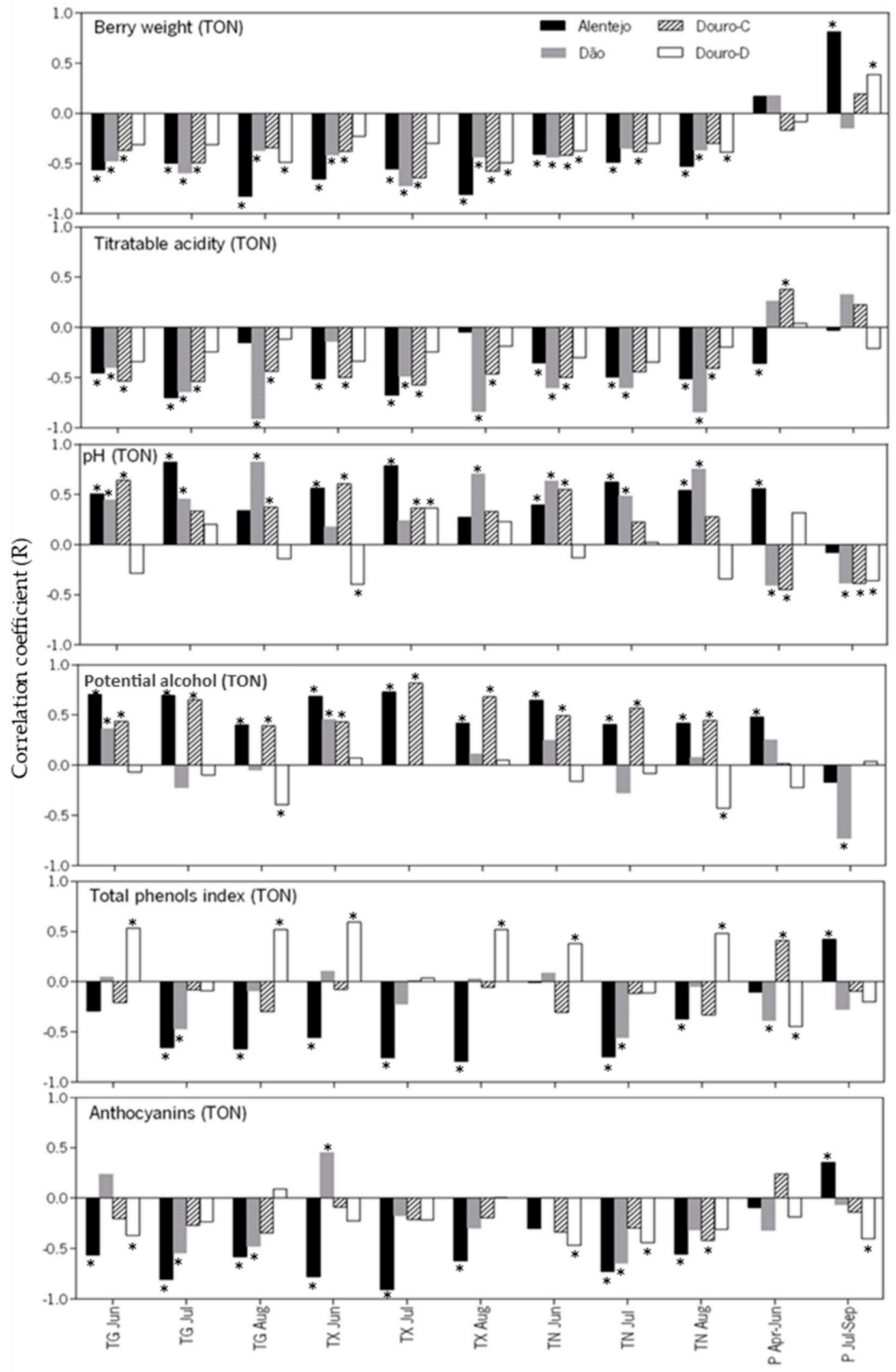

Figure 2. Pearson product-moment correlation coefficients between grape berry quality parameters (berry weight, titratable acidity, $\mathrm{pH}$, potential alcohol, total phenols index and anthocyanins) at maturity and climate variables for cv. Touriga Nacional (TON). Months are described by their initial letters. TG-average temperature; $\mathrm{TX}$-maximum temperature; $\mathrm{TN}$-minimum temperature; $\mathrm{P}$ - precipitation. Statistically significant correlation coefficients at $1 \%$ significance level are highlighted with an *. 


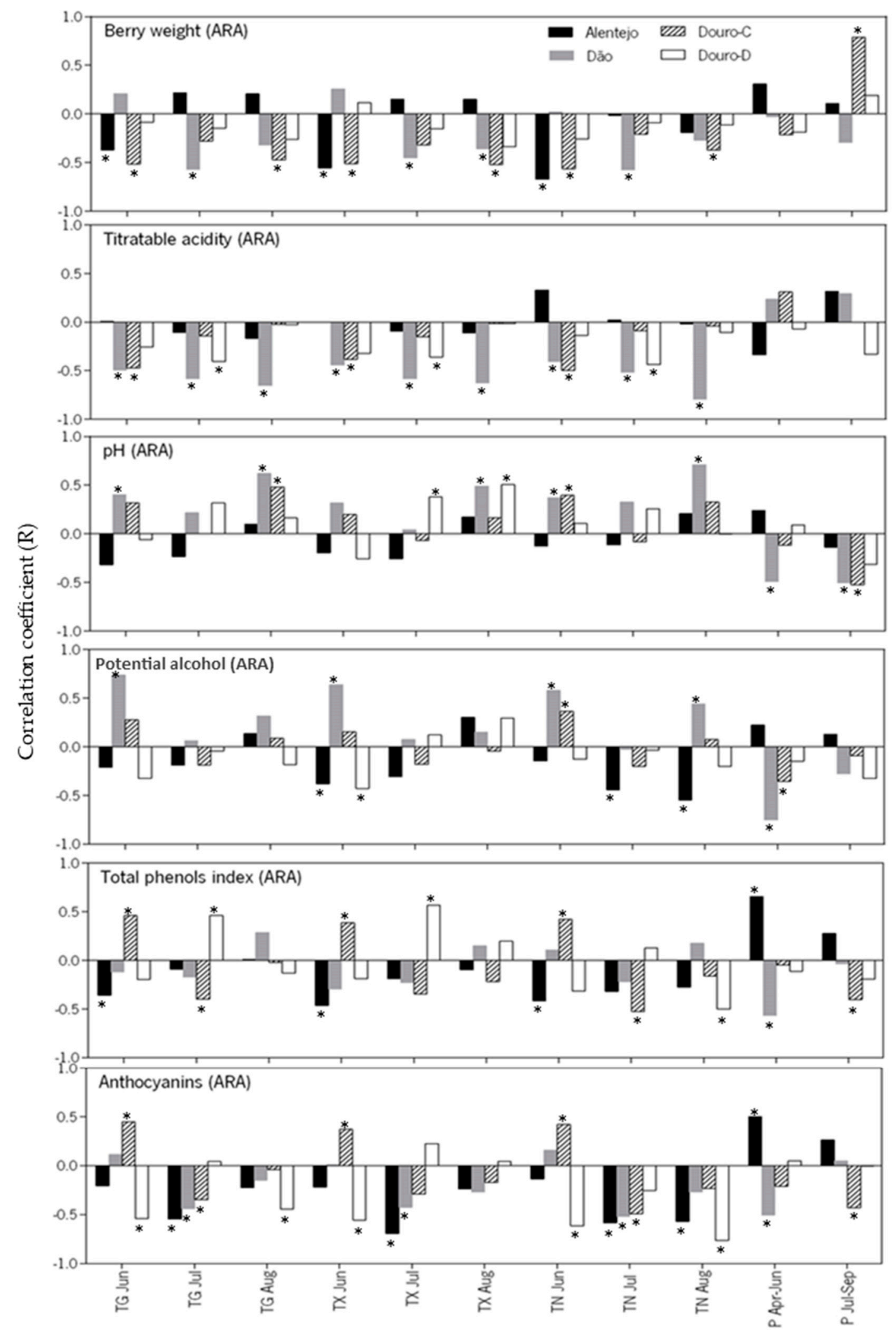

Figure 3. Pearson product-moment correlation coefficients between grape berry quality parameters (berry weight, titratable acidity, $\mathrm{pH}$, potential alcohol, total phenols index and anthocyanins) at maturity and climate variables for cv. Aragonez (ARA). Months are described by their initial letters. TG-average temperature; $\mathrm{TX}$-maximum temperature; $\mathrm{TN}$-minimum temperature; $\mathrm{P}$ - precipitation. Statistically significant correlation coefficients at $1 \%$ significance level are highlighted with an *. 


\subsection{Assessment of Relations through a Clustering Approach}

As reported previously, the maturation parameters of each site were grouped into two clusters: cluster 1 (years where the maturation parameter is higher than the median) and cluster 2 (years where the maturation parameter is lower than the median). The composition of the different clusters is indicated in Figure 4. The corresponding cluster-means (centroids) and the statistical significance of the respective differences are shown in Figure 5 . The differences between averages of cluster 1 and 2 were significant $(p \leq 0.05)$ for all studied berry parameters and regions, except for TA in Alentejo and TPI in Alentejo and Douro-D (Touriga Nacional) $(p>0.05)$, thus showing that the clusters comprise vintages with notably different grape berry attributes.
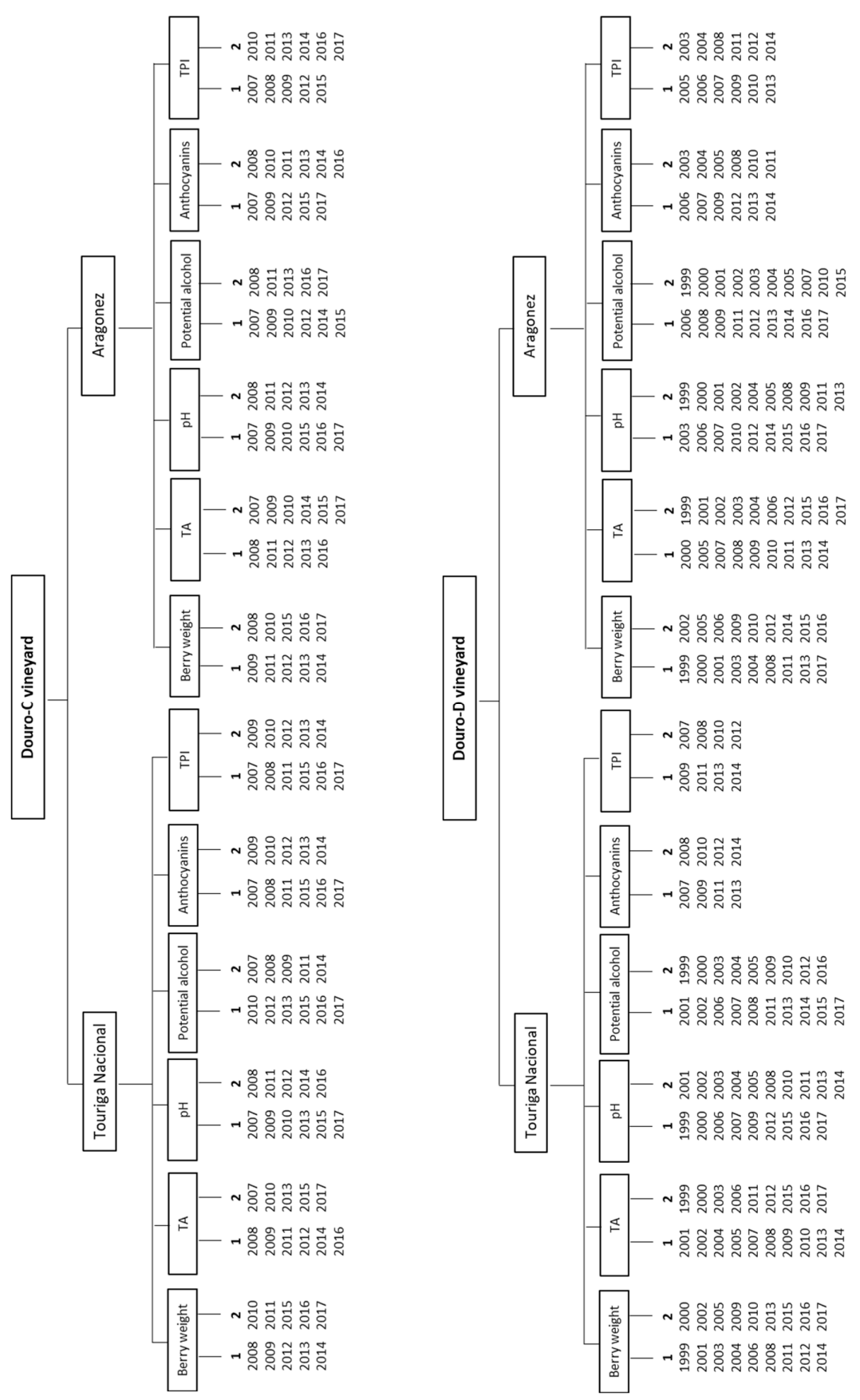

Figure 4. Cont. 


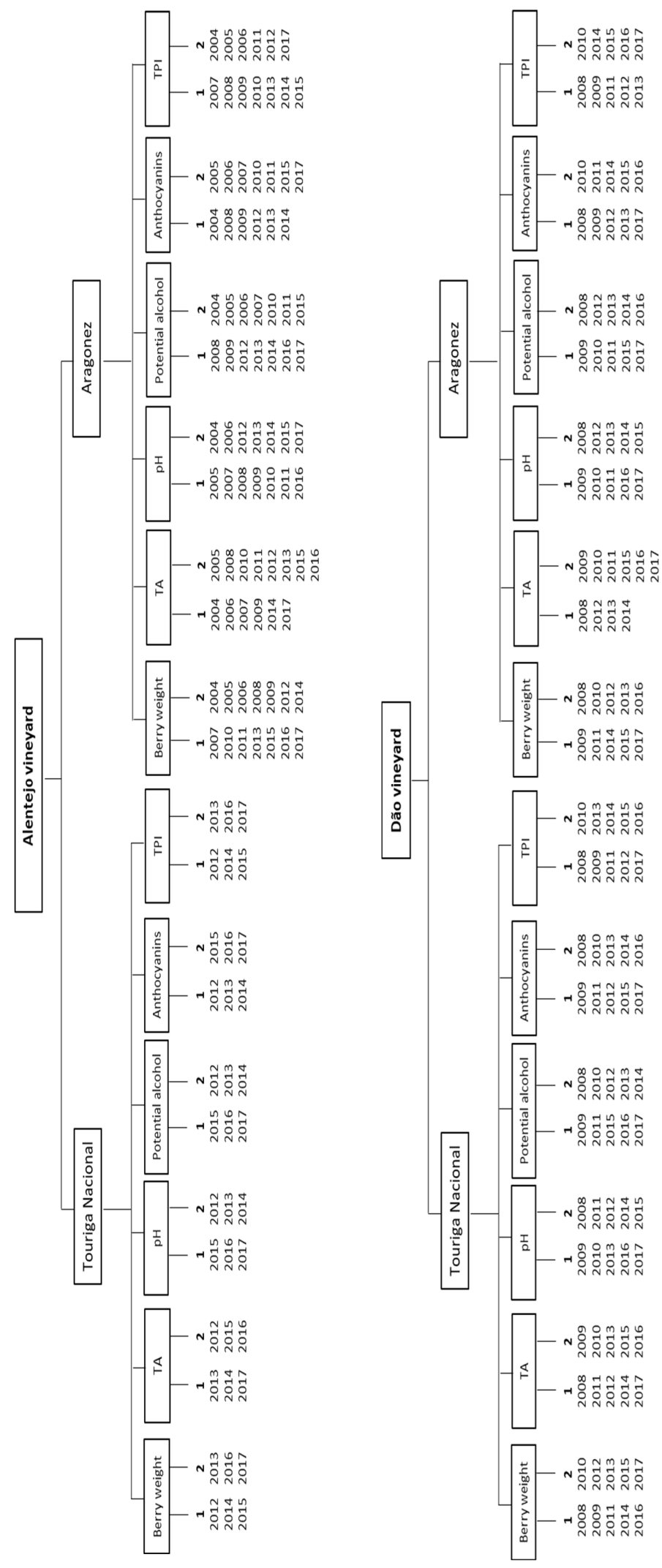

Figure 4. Identification of the years keyed to the different clusters for each quality parameter and vineyard site (Douro-C, Douro-D, Dão and Alentejo). 
Figure 5 also hints at differences in berry composition between cooler and warmer regions. Generally, in warmer regions and with lower annual precipitation (Alentejo and Douro-D, Table 2), berry weight and TA were lower than in cooler regions and with higher annual precipitation (Dão and Douro-C). Conversely, the berry $\mathrm{pH}$ was higher in warmer regions. Potential alcohol level at maturity did not show a clear trend across regions. Even so, the highest potential alcohol level in ARA berries was observed in the warmer region (Alentejo) and was significantly different from the lowest level observed in the cooler region (Dão). The TPI was very similar in all regions for both clusters, although a slight decrease (from the warmer to the colder region) was observed for ARA. Anthocyanins at maturity did not show a clear trend across regions.

The grape berry compositions for Alentejo, Dão and Douro- $C$ were noticeably affected by climatic conditions and will then be analysed in greater detail. For Douro-D, however, no such clear associations were found, and the respective results are not shown for the sake of succinctness. The difference between monthly averages of TG, TX and TN for June, July and August between maturation clusters was calculated for each site and variety (Tables 4 and 5). This analysis allowed the identification of temperature differences that may explain the average difference in grape quality attributes between clusters. The temperature differences were associated with an increase in the grape quality parameter (cluster 1 - cluster 2).

The results confirmed that higher temperature tends to lead to a reduction in berry weight, TA, anthocyanins and TPI (Tables 4 and 5). Conversely, lower temperature often induced a reduction in $\mathrm{pH}$ and potential alcohol. In general, significant temperature differences between clusters were lower for ARA. At large, higher temperature differences between clusters were found in July TX and for TON. In all studied regions, larger temperature differences between clusters were observed for TON in Alentejo and all parameters but TA. Temperature differences for TA clusters were higher for Dão. In Douro-C, the larger differences were found between potential alcohol clusters.

Table 4. Difference (in ${ }^{\circ} \mathrm{C}$ ) between the clusters for monthly means of TX, TG and TN in June, July and August for TON (cv. Touriga Nacional). ${ }^{*} p \leq 0.05,{ }^{* *} p \leq 0.01,{ }^{* * *} p \leq 0.001$. Only statistically significant differences are shown.

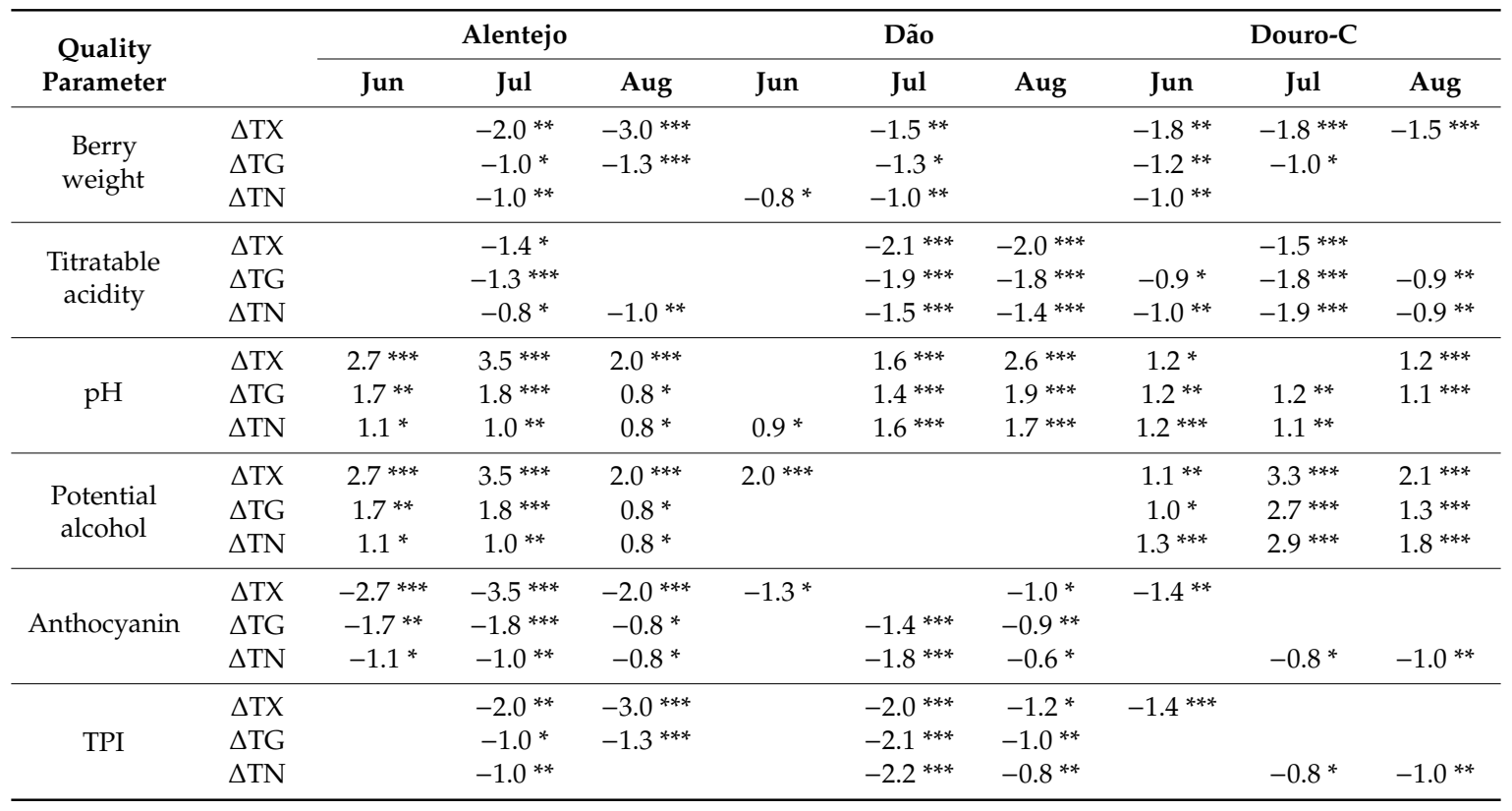



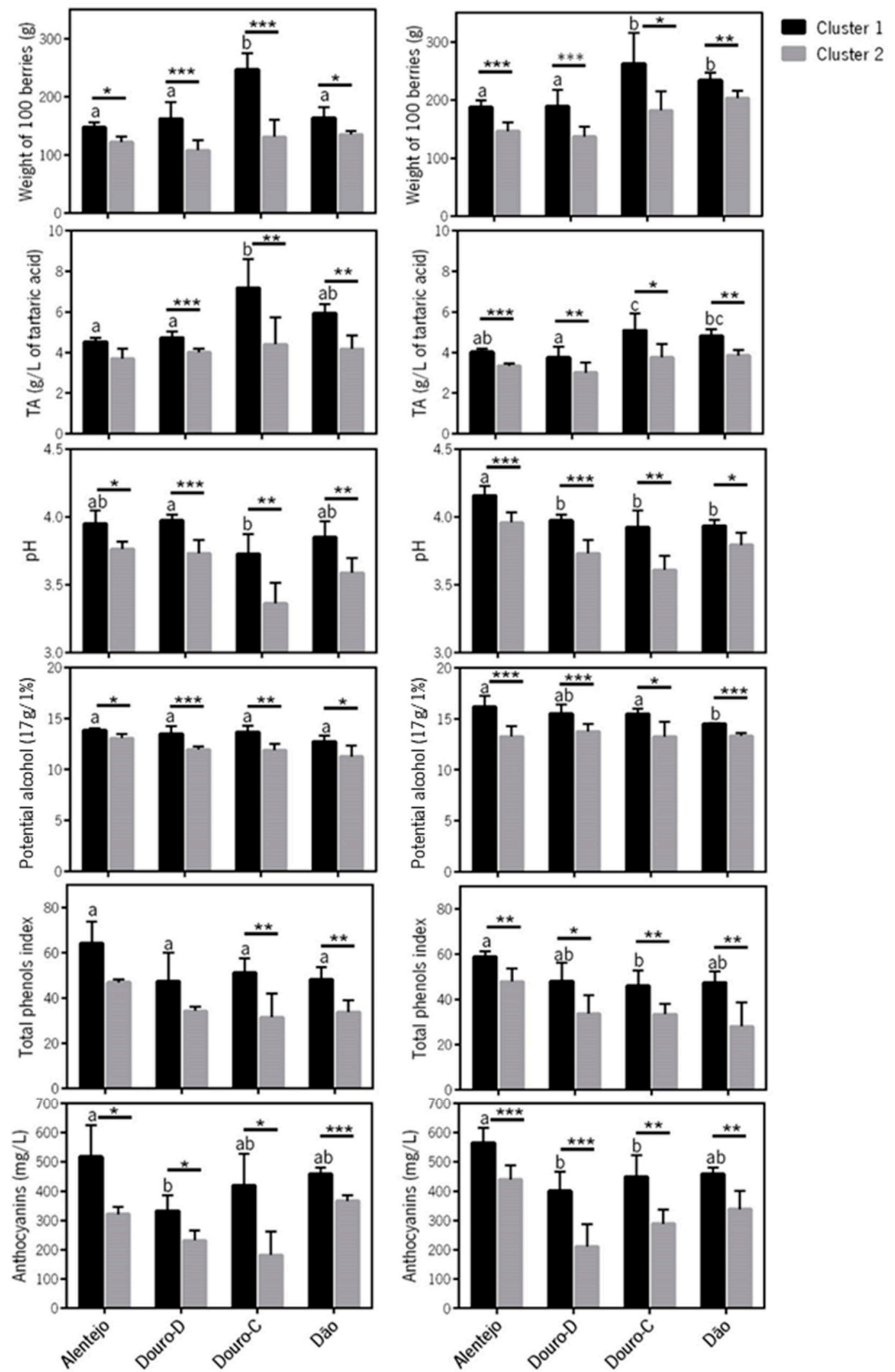

Figure 5. Grape berry quality parameters at maturity for TON (left panel) and ARA (right panel). The sites are listed from left to right according to average GST (April to October) in decreasing order. The bars represent the cluster-mean, the whiskers the standard deviation and statistically significant differences between clusters are indicated by asterisks $\left({ }^{*} p \leq 0.05,{ }^{* *} p \leq 0.01,{ }^{* * *} p \leq 0.001\right)$. Different letters indicate statistically significant differences between regions (for cluster 1 ). 
Table 5. Difference (in ${ }^{\circ} \mathrm{C}$ ) between the clusters for monthly means of TX, TG and TN in June, July and August for ARA (cv. Aragonez). ${ }^{*} p \leq 0.05,{ }^{* *} p \leq 0.01,{ }^{* * *} p \leq 0.001$. Only statistically significant differences are shown.

\begin{tabular}{|c|c|c|c|c|c|c|c|c|c|c|}
\hline \multirow{2}{*}{$\begin{array}{c}\text { Quality } \\
\text { Parameter }\end{array}$} & & \multicolumn{3}{|c|}{ Alentejo } & \multicolumn{3}{|c|}{ Dão } & \multicolumn{3}{|c|}{ Douro-C } \\
\hline & & Jun & Jul & Aug & Jun & Jul & Aug & Jun & Jul & Aug \\
\hline \multirow{3}{*}{$\begin{array}{c}\text { Berry } \\
\text { weight }\end{array}$} & $\Delta \mathrm{TX}$ & $-1.1^{*}$ & & & $-1.2 *$ & $-1.4^{* *}$ & $-1.1 *$ & $-1.9^{* * *}$ & $-1.6^{* * *}$ & \\
\hline & $\Delta \mathrm{TG}$ & 1.1 & & & & $-1.4^{* * *}$ & $-0.9^{* *}$ & $-1.5^{* * *}$ & $-1.3^{* * *}$ & \\
\hline & $\Delta \mathrm{TN}$ & $-1.0^{* * *}$ & & & & $-1.2^{* * *}$ & & $-1.3^{* * *}$ & $-1.1 * *$ & \\
\hline \multirow{3}{*}{$\begin{array}{c}\text { Titratable } \\
\text { acidity }\end{array}$} & $\Delta \mathrm{TX}$ & & & & $-2.1^{* * *}$ & $-1.3 *$ & $-1.2 * *$ & & & \\
\hline & $\Delta \mathrm{TG}$ & & & & $-1.3 * *$ & & $-1.0 * *$ & & & \\
\hline & $\Delta \mathrm{TN}$ & & & & & & $-1.3^{* * *}$ & & & \\
\hline \multirow{3}{*}{$\mathrm{pH}$} & $\Delta \mathrm{TX}$ & & & & & & $1.5^{* * *}$ & & & \\
\hline & $\Delta \mathrm{TG}$ & & & & & & $1.2^{* * *}$ & & & \\
\hline & $\Delta \mathrm{TN}$ & & & & & & $1.5^{* * *}$ & & & \\
\hline \multirow{3}{*}{$\begin{array}{l}\text { Potential } \\
\text { alcohol }\end{array}$} & $\Delta \mathrm{TX}$ & & & & $2.0^{* *}$ & & & & & \\
\hline & $\Delta \mathrm{TG}$ & & & & $1.5^{* * *}$ & & & & & \\
\hline & $\Delta \mathrm{TN}$ & & & & $0.9 *$ & & & & & \\
\hline \multirow{3}{*}{ Anthocyanins } & $\Delta \mathrm{TX}$ & & $-1.1^{* *}$ & & & & & & & \\
\hline & $\Delta \mathrm{TG}$ & & $-0.7^{* *}$ & & & & & & & \\
\hline & $\Delta \mathrm{TN}$ & & & $-0.8^{* *}$ & & & & & & \\
\hline \multirow{3}{*}{ TPI } & $\Delta \mathrm{TX}$ & & & & & & & & & \\
\hline & $\Delta \mathrm{TG}$ & & & & & & & & & \\
\hline & $\Delta \mathrm{TN}$ & & & & & & & & & \\
\hline
\end{tabular}

\subsection{Relations on the Daily Timescale}

For the largest monthly temperature differences found between the clusters of the different quality parameters, daily temperature differences between clusters were calculated from June 1 to August 31 . This analysis allowed for identifying critical days/periods that may have contributed to the interannual variability of maturation parameters. Therefore, daily maximum temperature differences between clusters were carried out for Alentejo (berry weight, $\mathrm{pH}$, potential alcohol, TPI and anthocyanins), Dão (titratable acidity) and Douro-C (potential alcohol) samples of TON.

The mean differences (cluster 2 minus cluster 1) in the daily TX between the two clusters of berry weight and TPI for Alentejo (from 1 June to 31 August) showed that TX in cluster 1 was generally lower than those of cluster 2, apart from a few exceptions (Figure 6a). Therefore, cluster 1 years (higher berry weight and TPI) were consistently cooler than cluster 2 years (lower berry weight and TPI). Moreover, cooler years were associated with higher anthocyanins levels (Figure $6 \mathrm{~b}$ ) and lower $\mathrm{pH}$ and potential alcohol levels (Figure 6c) in Alentejo. For titratable acidity in Dão, Figure 6d highlights that the years of cluster 1 (higher titratable acidity levels) had generally lower values of TX than those of cluster 2 (lower titratable acidity levels). Lastly, for the potential alcohol in Douro-C, Figure 6e shows that daily TX of cluster 1 years (higher potential alcohol) was generally higher than those of cluster 2 (lower potential alcohol).

The aforementioned relationships on the daily time scale suggest some predictive potential. This should be, however, explored in greater detail in forthcoming studies, using more advanced and suitable statistical methodologies, such as the application of predictive regression analysis and low-pass filters to smooth out the high-frequency signals, but this is out of the scope of the present exploratory study. 

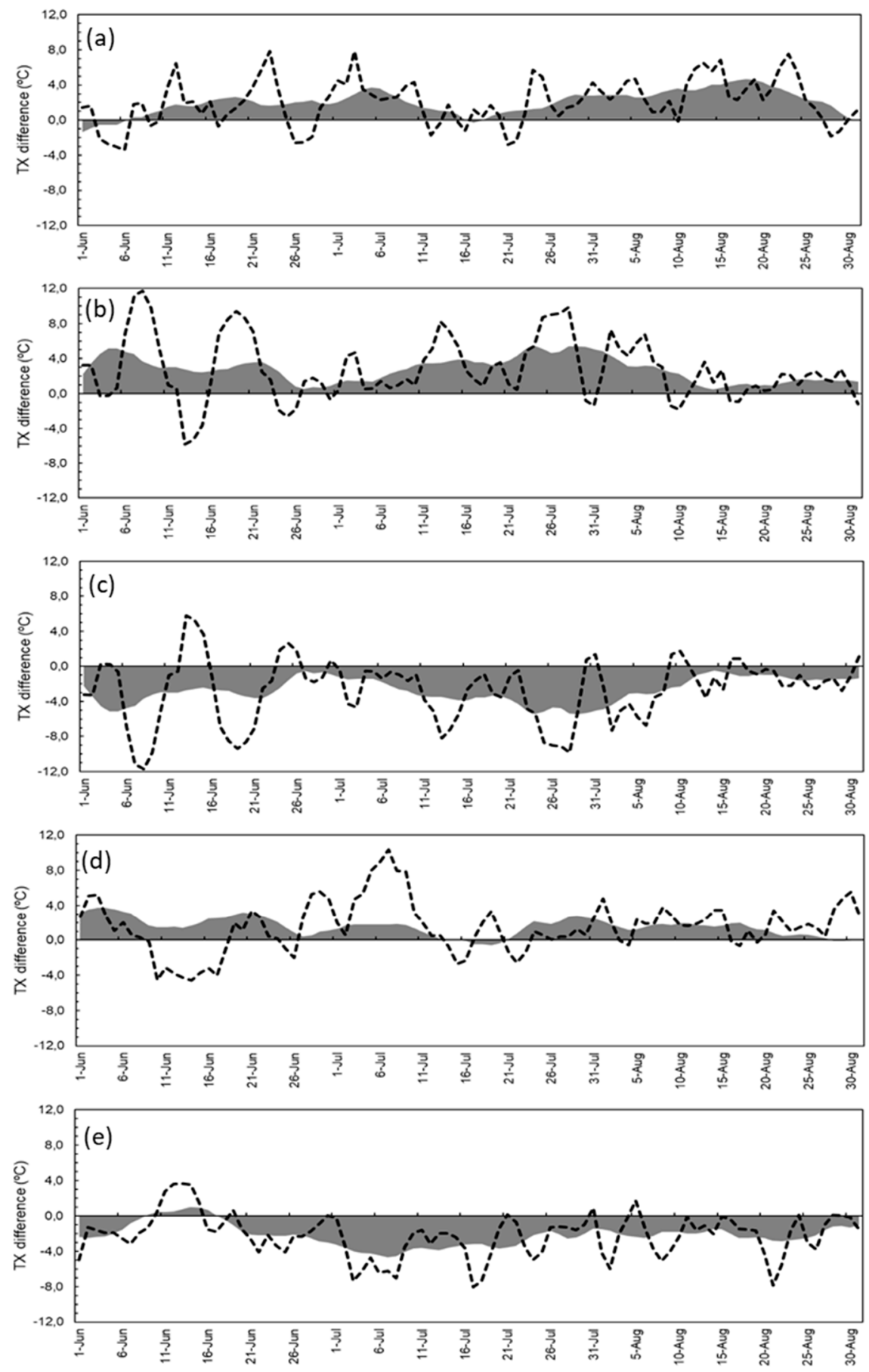

Figure 6. Cluster 2 - Cluster 1 differences in the mean TX (in ${ }^{\circ} \mathrm{C}$ ) from 1 June to 31 August (dashed lines) for: (a) berry weight and total phenols index in Alentejo; (b) anthocyanins in Alentejo; (c) pH and potential alcohol in Alentejo; (d) titratable acidity in Dão; (e) potential alcohol in Douro-C. All parameters are for TON. The 11-day moving averages are also outlined (grey shaded areas).

\section{Discussion}

For the four selected vineyards (Alentejo, Dão, Douro-C and Douro-D), berry weight of TON (Touriga Nacional) and ARA (Aragonez) at maturity was negatively influenced by temperature, while strong positive correlations with precipitation (July to September) were found in Alentejo (TON) and Douro-C (ARA) (Figures 2 and 3). As vine water availability is closely related to temperature, an increase in temperature can lead to water deficit. Some studies have shown that when the vine is 
exposed to water stress, berry weight decreases $[28,48,49]$, as water deficit generally leads to smaller berries, by inhibiting both cell division and cell expansion [12,50].

For both grapevine varieties (TON and ARA), TA was negatively correlated with all monthly temperatures (TX, TG and TN) between June to August, while correlations with precipitation were generally positive but weak (Figures 2 and 3). Temperature enhances the respiration of tartaric and malic acids, thus leading to a drop in TA and increased $\mathrm{pH}[13,14]$. The observed positive influence of precipitation on TA levels at maturity for Dão and Douro-C is supported by previous studies $[14,17,51]$. However, the negative influence of precipitation in TA for Alentejo and Douro-D (Figures 2 and 3) was not originally expected and may be explained by the fact that these two vineyard sites are irrigated. However, future studies should focus on factors other than precipitation, such as atmospheric humidity and soil water holding capacity, since they also determine the vine water status [10].

The correlations between $\mathrm{pH}$ and monthly TX, TG and TN were generally positive, also in accordance with previous studies [14]. The associations between $\mathrm{pH}$ and precipitation variables were negative (more precipitation leads to lower $\mathrm{pH}$ ), except for Alentejo and Douro-D (April to June), which is in accordance with the correlations with TA (Figures 2 and 3). The fact that the strength of the correlations between climate variables and $\mathrm{pH}$ is lower than between climate variables and TA (more evident for ARA) is possibly explained by previous results showing that $\mathrm{pH}$ is more affected by the canopy microclimate than TA [52]. Future studies with microclimate data may further clarify these correlations.

The correlation analysis between climate variables and potential alcohol was dependent on the regions and varieties. In Alentejo and Douro-C (TON) and Dão (ARA), temperature had a strong positive influence on potential alcohol levels, despite the weak negative influences in Douro-D. Moreover, the strongest correlations were found between PA and monthly temperatures of June and July (fruit set/veraison period) (Figures 2 and 3). In agreement with previous reports, these results showed that total soluble solids (TSS, an equivalent measure to PA) accumulation was stimulated by high temperatures at veraison and a few days after [20,21]. A strong negative correlation between PA and precipitation was only found in Dão for both varieties studied (rainfed vineyard), while a moderate positive correlation was found in Alentejo (irrigated vineyard) (Figures 2 and 3). As previously described, under irrigated conditions, TSS concentration can be decreased by unexpected precipitation due to the dilution effect caused by greater berry size [17]. Nonetheless, other reports have shown that the accumulation of sugar is improved in irrigated vines due to a stimulation of the photosynthetic activity [22] in semi-arid regions. Thus, based on previous studies, both positive and negative correlations between PA and precipitation may occur, depending on the specific site conditions.

The optimum temperature for phenolic accumulation is approximately $25^{\circ} \mathrm{C}$ [20]. Therefore, both the positive and negative correlations (Figures 2 and 3) can be explained by the temperature differences between regions. Alentejo is characterized by GST higher than the other regions, which may explain the observed decrease of total phenols levels with temperature. However, the analysis of the impact of climatic variables on TPI is ambiguous since the impact of an environmental factor on each phenolic compound may be different. Our results showed that TPI can be reduced or increased depending on the region and precipitation period. It has been shown that the phenolic compound biosynthesis can be stimulated or inhibited depending on the type of phenolic compound, severity of water deficit and the period when the water deficit occurs [26]. On the other hand, the positive effect of water stress on phenolics concentration can be explained by the reduced berry size under water limitation [26]. Surface area/volume ratio of the berries increases with the decrease of berry size. Then, since phenolic compounds accumulate in the berry skin, smaller berries have a relatively greater solute to solvent ratio than larger berries [12].

Results showed that anthocyanins are negatively correlated with all monthly temperatures (TX, TG and TN) from June to August (Figures 2 and 3). Previous reports have shown that high temperatures negatively affect the content of anthocyanins at harvest due to an impairment of biosynthesis [21] and/or accelerated degradation [25]. For both varieties, the TN in July and August 
was the most influential variable in all regions. According to a previous study [30], for nocturnal temperature above and below $15^{\circ} \mathrm{C}$, grape berry anthocyanins are reduced and enhanced, respectively. The correlations between precipitation and anthocyanins (Figures 2 and 3) are different from one region to another. Specifically, a moderate positive correlation was found for Alentejo and a moderate negative correlation for Dão in April-June period (Aragonez). Enhanced water availability early in the growing season is beneficial, because it promotes vegetative growth and, consequently, berry development and its composition at later stages [29], thus explaining the positive correlation found in Alentejo. On the other hand, excessive moisture late in the growing season has been described to reduce anthocyanins content [30], though this effect is not clear in our results.

The analysis of berry quality parameters at maturity across regions showed that the lowest levels of berry weight and TA occurred more frequently in warmer sites with low annual precipitation (Alentejo and Douro-D). Accordingly, in the cooler sites, with higher annual precipitation (Douro-C and Dão), berry weight and TA were higher (opposite effect observed with $\mathrm{pH}$ ). The difference between warmer and cooler regions relative to berry weight, TA and $\mathrm{pH}$ was particularly well established. Moreover, berry weight and TA levels were more negatively affected in warmer than in the cooler years, while $\mathrm{pH}$ was more negatively affected in cooler than in warmer years (Figure 5).

Anthocyanins at maturity did not show a clear trend across regions when only the average temperature of the growing season was considered. However, precipitation levels influenced berry anthocyanins. Low levels of precipitation in Alentejo may have accounted for high anthocyanins content when compared to other regions (even with higher temperatures). Apart from that, in Alentejo, the highest anthocyanins content was in the coolest years and lowest in warmer years. Higher minimum temperatures recorded in Douro-D vineyard can explain lower anthocyanins levels (Figure 5). The positive effect of low minimum temperatures during ripening on anthocyanins accumulation was already reported [30].

The highest sugar content was associated with warmer years, and an opposite effect was observed in the coolest years (Figure 5), which is in agreement with previous reports [13]. Water limitation, often associated with heat stress, may affect plant hormonal equilibrium and berry weight, and compromise sugar accumulation in grape berries [13].

The influence of precipitation on berry composition at maturity varied from one region to another and between varieties (Figures 2 and 3). Although some results have shown a role of precipitation during flowering and maturation period, other variables, such as soil water holding capacity and air relative humidity, should be considered to guarantee that the associations found with precipitation are not being influenced by other important determinants of the plant water status. On the other hand, some of the studied vineyards were irrigated for part of the time period studied (Alentejo and Douro-D), which limits the study of precipitation influence on berry composition.

In general, the results showed that grape berry quality parameters of the ARA variety are less affected by interannual climatic variability than the TON variety. Thus, ARA seems to be more resilient to climatic variations, which is reflected in their grape berry composition, namely in the studied grape berry quality parameters. The physiological response of grapevines to environmental stress is complex and not yet completely understood. It depends on the genotype and is largely influenced by both rootstock and scion traits. Concerning scion traits, leaf stomatal regulation is a key parameter influencing plant water relations [53]. Thus, one explanation for the obtained results may arise from the fact that ARA shows isohydric behaviour, while TON shows anisohydric behaviour [54]. These terms are related to stomatal regulation, such that some genotypes display better stomatal regulation under water stress than others, being classified as isohydric (drought avoiders or 'pessimistic'). In turn, anisohydric ('optimistic') genotypes have less control of stomatal aperture under water stress [53].

In Semillon variety (anisohydric), high stomatal conductance during the day results in an incomplete rehydration before dawn, especially during warm and windy nights, which affected grape berry composition [55]. A similar behaviour could account for the results obtained in the present study for TON. This variety displays a high capacity of heat dissipation via evaporative cooling, which can 
facilitate adaptation to warmer climates under plentiful water supply, such as in irrigated vines $[54,56]$. However, for rainfed TON vineyards, the adaptation to warmer climates by evaporative cooling is limited. Moreover, TON may face early senescence of basal leaves and further leaf drop, with negative consequences for berry quality [53]. Therefore, isohydric varieties are more tolerant to drought/water stress than the anisohydric ones. Whether or not isohydric, some genotypes have different behaviour according to growing conditions (e.g., field versus greenhouse) and the degree of stress imposed on vines [57]. However, in this study, a comparison between varieties was carried out in the same regions and over the same growing conditions, using a plural number of genotypes and a wide range of plant age on each. Hence, the different behaviour of TON and ARA regarding stomatal regulation is likely an important physiological condition that accounts for the observed results.

In this study, the influences of climate variables on grape berry composition were examined at maturity (last analysis carried out before harvest, up to two weeks before), so the established common maturity level is influenced by the winemaker's decision to harvest, which could have introduced a variation between samples. This additional source of variation could be minimised by fixing a common maturity date (e.g., when the crop first reaches $22^{\circ}$ Brix TSS [14]), but this type of experimental methodology is not possible to implement in a study like the one performed here, which was based on maturity data from different regions and over a large period.

\section{Conclusions}

For the studied sites in Portugal (Douro, Dão and Alentejo) and their environmental conditions, at berry maturity, high temperatures tend to decrease berry weight, titratable acidity, anthocyanins and TPI, and increase $\mathrm{pH}$ and potential alcohol. Concerning precipitation, its influence was largely dependent on location and variety. Although these outcomes are in line with previous findings and were thereby expected, this study is unprecedented for Portugal, as it is based on a large systematised and comprehensive database of grape berry maturity parameters. After identifying the most important climatic variables, the development of a model to be used for both operational short-to-medium range prediction and climate change impact assessments should be envisioned in future research. The grape maturation database that was prepared in the context of the present study still contains crucial information that can be further exploited to increase the level of knowledge about the influence of climatic variability on grape composition. In particular, it would be interesting: (i) to search correlations between climatic variables and grape quality parameters not studied in this work, such as malic acid, and to the varietal aromatic potential; (ii) to extend the study to other regions and varieties; and (iii) to examine the interaction of soil/weather/morphology of the territory.

Author Contributions: Conceptualization and methodology, all authors; software, C.C.; validation, C.C.; formal analysis, C.C.; investigation, all authors; resources, C.C. and A.G.; data curation, C.C., N.F., M.T. and A.G.; writing-original draft preparation, C.C. and J.A.S. writing—review and editing, all authors; visualization, C.C.; supervision, H.G., A.G. and J.A.S.; project administration, N.F. and A.G.; funding acquisition, J.A.S. All authors have read and agreed to the published version of the manuscript.

Funding: This study was funded by the Clim4Vitis project_- “Climate change impact mitigation for European viticulture: knowledge transfer for an integrated approach", funded by European Union's Horizon 2020 Research and Innovation Programme, under grant agreement no. 810176.

Acknowledgments: This work was supported by the “Contrato-Programa” UIDB/04050/2020 and UIDB/04033/2020 funded by national funds through the FCT I.P. The work was also supported by FCT and European Funds (FEDER/POCI/COMPETE2020) through the research projects MitiVineDrought (PTDC/BIA-FBT/30341/2017 and POCI-01-0145-FEDER-030341). The study was also supported by FCT-Portuguese Foundation for Science and Technology, under the project UIDB/04033/2020.

Conflicts of Interest: The authors declare no conflicts of interest. The funders had no role in the design of the study; in the collection, analyses, or interpretation of data; in the writing of the manuscript, or in the decision to publish the results. 


\section{References}

1. Organisation Internationale de la Vigne et du vin. 2019 Statistical Report on World Vitiviniculture; International Organisation of Vine and Wine: Paris, France, 2019.

2. Fontoin, H.; Saucier, C.; Teissedre, P.-L.; Glories, Y. Effect of pH, ethanol and acidity on astringency and bitterness of grape seed tannin oligomers in model wine solution. Food Qual. Prefer. 2008, 19, $286-291$. [CrossRef]

3. Jones, G.; Reid, R.; Vilks, A. Climate, Grapes, and Wine: Structure and Suitability in a Variable and Changing Climate. In The Geography of Wine; Springer: Dordrecht, The Netherlands, 2012; pp. 109-133. [CrossRef]

4. Bonada, M.; Sadras, V.O. Critical appraisal of methods to investigate the effect of temperature on grapevine berry composition. Aust. J. Grape Wine Res. 2015, 21, 1-17. [CrossRef]

5. Fraga, H.; Santos, J.A.; Moutinho-Pereira, J.; Carlos, C.; Silvestre, J.; Eiras-Dias, J.; Mota, T.; Malheiro, A.C. Statistical modelling of grapevine phenology in Portuguese wine regions: Observed trends and climate change projections. J. Agric. Sci. 2016, 154, 795-811. [CrossRef]

6. Costa, R.; Fraga, H.; Fonseca, A.; de Cortazar-Atauri, I.G.; Val, M.C.; Carlos, C.; Reis, S.; Santos, J.A. Grapevine Phenology of cv. Touriga Franca and Touriga Nacional in the Douro Wine Region: Modelling and Climate Change Projections. Agronomy 2019, 9, 210. [CrossRef]

7. Bock, A.; Sparks, T.H.; Estrella, N.; Menzel, A. Climate-Induced Changes in Grapevine Yield and Must Sugar Content in Franconia (Germany) between 1805 and 2010. PLoS ONE 2013, 8, e69015. [CrossRef] [PubMed]

8. Santos, J.; Graetsch, S.; Karremann, M.; Jones, G.; Pinto, J. Ensemble projections for wine production in the Douro Valley of Portugal. Clim. Chang. 2013, 117, 211-225. [CrossRef]

9. Mira de Orduña, R. Climate change associated effects on grape and wine quality and production. Food Res. Int. 2010, 43, 1844-1855. [CrossRef]

10. Gladstones, J. Viticulture and Environment; Winetitles: Adelaide, Australia, 1992.

11. Ashenfelter, O.; Storchmann, K. Wine and Climate Change. Am. Assoc. Wine Econ. 2014, 164854, 319-343. [CrossRef]

12. Conde, C.; Silva, P.; Fontes, N.; Dias, A.; Tavares, R.; Sousa, M.; Agasse, A.; Delrot, S.; Gerós, H. Biochemical changes throughout Grape Berry development and fruit and wine quality. Food 2007, 1, 1-22.

13. Ubalde, J.M.; Sort, X.; Zayas, A.; Poch, R.M. Effects of Soil and Climatic Conditions on Grape Ripening and Wine Quality of Cabernet Sauvignon. J. Wine Res. 2010, 21, 1-17. [CrossRef]

14. Barnuud, N.N.; Zerihun, A.; Gibberd, M.; Bates, B. Berry composition and climate: Responses and empirical models. Int. J. Biometeorol. 2014, 58, 1207-1223. [CrossRef] [PubMed]

15. Buttrose, M.S.; Hale, C.R.; Kliewer, W.M. Effect of Temperature on the Composition of Cabernet Sauvignon Berries. Am. J. Enol. Vitic. 1971, 22, 71-75.

16. Ruffner, H.P.; Hawker, J.S.; Hale, C.R. Temperature and enzymic control of malate metabolism in berries of Vitis vinifera. Phytochemistry 1976, 15, 1877-1880. [CrossRef]

17. Lopez, M.I.; Sanchez, M.T.; Diaz, A.; Ramirez, P.; Morales, J. Influence of a deficit irrigation regime during ripening on berry composition in grapevines (Vitis vinifera L.) grown in semi-arid areas. Int. J. Food Sci. Nutr. 2007, 58, 491-507. [CrossRef]

18. Coombe, B.G. Influence of temperature on composition and quality of grapes. Acta Hortic. 1987, 206, $23-36$. [CrossRef]

19. Keller, M. Managing grapevines to optimise fruit development in a challenging environment: A climate change primer for viticulturists. Aust. J. Grape Wine Res. 2010, 16, 56-69. [CrossRef]

20. Poudel, P.R.; Mochioka, R.; Beppu, K.; Kataoka, I. Influence of temperature on berry composition of interspecific hybrid wine grape 'Kadainou R-1' (Vitis ficifolia var. ganebu $\times$ V. vinifera 'Muscat of Alexandria'). J. Jpn. Soc. Hortic. Sci. 2009, 78, 169-174. [CrossRef]

21. Mori, K.; Sugaya, S.; Gemma, H. Decreased anthocyanin biosynthesis in grape berries grown under elevated night temperature condition. Sci. Hortic. 2005, 105, 319-330. [CrossRef]

22. Bartolomé, M. Respuestas de la vid (Vitis vinifera L.) a Condiciones de Estrés Hídrico: Efectos Sobre las Relaciones Agua-Planta, el Crecimiento, la Producción y la Calidad (cv. Tempranillo); Universidad Politécnica de Madrid: Madrid, Spain, 1993. 
23. Cacho, J.; Fernández, P.; Ferreira, V.; Castells, J.E. Evolution of Five Anthocyanidin-3-Glucosides in the Skin of the Tempranillo, Moristel, and Garnacha Grape Varieties and Influence of Climatological Variables. Am. J. Enol. Vitic. 1992, 43, 244-248.

24. Lorrain, B.; Chira, K.; Teissedre, P.-L. Phenolic composition of Merlot and Cabernet-Sauvignon grapes from Bordeaux vineyard for the 2009-vintage: Comparison to 2006, 2007 and 2008 vintages. Food Chem. 2011, 126, 1991-1999. [CrossRef]

25. Mori, K.; Goto-Yamamoto, N.; Kitayama, M.; Hashizume, K. Loss of anthocyanins in red-wine grape under high temperature. J. Exp. Bot. 2007, 58, 1935-1945. [CrossRef] [PubMed]

26. Ojeda, H.; Andary, C.; Kraeva, E.; Carbonneau, A.; Deloire, A. Influence of pre- and post-veraison water deficit on synthesis and concentration of skin phenolic compounds during berry growth of Vitis Vinifera cv. Shiraz. Am. J. Enol. Vitic. 2002, 53, 261-267.

27. Matthews, M.; Anderson, M.M. Fruit ripening in Vitis vinifera L. responses to seasonal water deficits. Am. J. Enol. Vitic. 1988, 39, 313-320.

28. Castellarin, S.D.; Pfeiffer, A.; Sivilotti, P.; Degan, M.; Peterlunger, E.; Di Gaspero, G. Transcriptional regulation of anthocyanin biosynthesis in ripening fruits of grapevine under seasonal water deficit. Plant Cell Environ. 2007, 30, 1381-1399. [CrossRef] [PubMed]

29. Keller, M.; Tarara, J.M.; Mills, L.J. Spring temperatures alter reproductive development in grapevines. Aust. J. Grape Wine Res. 2010, 16, 445-454. [CrossRef]

30. Jackson, D.I.; Lombard, P.B. Environmental and Management Practices Affecting Grape Composition and Wine Quality-A Review. Am. J. Enol. Vitic. 1993, 44, 409-430.

31. Cogato, A.; Meggio, F.; Pirotti, F.; Cristante, A.; Marinello, F. Analysis and impact of recent climate trends on grape composition in north-east Italy. BIO Web. Conf. 2019, 13. [CrossRef]

32. Jones, G.V.; Davis, R.E. Climate influences on grapevine phenology, grape composition, and wine production and quality for Bordeaux, France. Am. J. Enol. Vitic. 2000, 51, 249-261.

33. Cunha, M.; Abreu, I.; Pinto, P.; Castro, R.d. Airborne Pollen Samples for Early-Season Estimates of Wine Production in a Mediterranean Climate Area of Northern Portugal. Am. J. Enol. Vitic. 2003, 54, 189-194.

34. Santos, J.A.; Fraga, H.; Malheiro, A.C.; Moutinho-Pereira, J.; Dinis, L.-T.; Correia, C.; Moriondo, M.; Leolini, L.; Dibari, C.; Costafreda-Aumedes, S.; et al. A Review of the Potential Climate Change Impacts and Adaptation Options for European Viticulture. Appl. Sci. 2020, 10, 3092. [CrossRef]

35. Blouin, J.; Peynaud, É. Connaissance et Travail du Vin, 3rd ed.; Dunod: Paris, France, 2001.

36. Saint-Cricq, N.; Vivas, N.; Glories, Y. Maturité phénolique: Définition et contrôle. Rev. Française Oenologie 1998, 173, 22-25.

37. Fonseca, A.R.; Santos, J.A. High-Resolution Temperature Datasets in Portugal from a Geostatistical Approach: Variability and Extremes. J. Appl. Meteorol. Clim. 2018, 57, 627-644. [CrossRef]

38. Wilks, D.S. Statistical Methods in the Atmospheric Sciences, 4th ed.; Elsevier: Cambridge, MA, USA, 2019.

39. Santos, M.; Fonseca, A.; Fraga, H.; Jones, G.V.; Santos, J.A. Bioclimatic conditions of the Portuguese wine denominations of origin under changing climates. Int. J. Climatol. 2020, 40, 927-941. [CrossRef]

40. Fraga, H.; Atauri, I.G.D.; Santos, J.A. Viticultural irrigation demands under climate change scenarios in Portugal. Agric. Water Manag. 2018, 196, 66-74. [CrossRef]

41. Santos, J.A.; Pinto, J.G.; Ulbrich, U. On the development of strong ridge episodes over the eastern North Atlantic. Geophys. Res. Lett. 2009, 36. [CrossRef]

42. Santos, J.; Corte-real, J.; Leite, S. Atmospheric large-scale dynamics during the 2004/2005 winter drought in Portugal. Int. J. Climatol. 2007, 27, 571-586. [CrossRef]

43. Fraga, H.; Atauri, I.G.D.; Malheiro, A.C.; Moutinho-Pereira, J.; Santos, J.A. Viticulture in Portugal: A review of recent trends and climate change projections. OENO One 2017, 51, 61-69. [CrossRef]

44. Santos, M.; Fragoso, M.; Santos, J.A. Regionalization and susceptibility assessment to daily precipitation extremes in mainland Portugal. Appl. Geogr. 2017, 86, 128-138. [CrossRef]

45. Santos, J.A.; Belo-Pereira, M. A comprehensive analysis of hail events in Portugal: Climatology and consistency with atmospheric circulation. Int. J. Climatol. 2019, 39, 188-205. [CrossRef]

46. Fraga, H.; Molitor, D.; Leolini, L.; Santos, J.A. What Is the Impact of Heatwaves on European Viticulture? A Modelling Assessment. Appl. Sci. 2020, 10, 3030. [CrossRef]

47. Santos, J.A.; Costa, R.; Fraga, H. New insights into thermal growing conditions of Portuguese grapevine varieties under changing climates. Appl. Clim. 2019, 135, 1215-1226. [CrossRef] 
48. Arrizabalaga, M.; Morales, F.; Oyarzun, M.; Delrot, S.; Gomes, E.; Irigoyen, J.J.; Hilbert, G.; Pascual, I. Tempranillo clones differ in the response of berry sugar and anthocyanin accumulation to elevated temperature. Plant Sci. 2018, 267, 74-83. [CrossRef] [PubMed]

49. Van Leeuwen, C.; Trégoat, O.; Choné, X.; Bois, B.; Pernet, D.; Gaudillère, J.-P. Vine water status is a key factor in grape ripening and vintage quality for red Bordeaux wine. How can it be assessed for vineyard management purposes? OENO One 2009, 43, 121-134. [CrossRef]

50. Dai, Z.W.; Ollat, N.; Gomès, E.; Decroocq, S.; Tandonnet, J.-P.; Bordenave, L.; Pieri, P.; Hilbert, G.; Kappel, C.; van Leeuwen, C.; et al. Ecophysiological, Genetic, and Molecular Causes of Variation in Grape Berry Weight and Composition: A Review. Am. J. Enol. Vitic. 2011, 62, 413-425. [CrossRef]

51. Salazar-Parra, C.; Aguirreolea, J.; Sánchez-Díaz, M.; Irigoyen, J.; Morales, F. Effects of climate change scenarios on Tempranillo grapevine (Vitis vinifera L.) ripening: Response to a combination of elevated $\mathrm{CO}_{2}$ and temperature, and moderate drought. Plant Soil. 2010, 337, 179-191. [CrossRef]

52. Smart, E.R. Principles of grapevine canopy microclimate manipulation with implications for yield and quality. A review. Am. J. Enol. Vitic. 1985, 36, 230-239.

53. Zarrouk, O.; Costa, J.M.; Francisco, R.; Lopes, C.; Chaves, M.M. Drought and water management in Mediterranean vineyards. In Grapevine in a Changing Environment; Gerós, H., Chaves, M.M., Medrano Gil, H., Delrot, S., Eds.; John Wiley \& Sons: New York, NY, USA, 2016; pp. 38-59.

54. Carvalho, L.C.; Coito, J.L.; Goncalves, E.F.; Chaves, M.M.; Amancio, S. Differential physiological response of the grapevine varieties Touriga Nacional and Trincadeira to combined heat, drought and light stresses. Plant Biol. 2016, 18, 101-111. [CrossRef]

55. Rogiers, S.Y.; Greer, D.H.; Hutton, R.J.; Landsberg, J.J. Does night-time transpiration contribute to anisohydric behaviour in a Vitis vinifera cultivar? J. Exp. Bot. 2009, 60, 3751-3763. [CrossRef]

56. Costa, J.M.; Ortuño, M.F.; Lopes, C.M.; Chaves, M.M. Grapevine varieties exhibiting differences in stomatal response to water deficit. Funct. Plant Biol. 2012, 39, 179-189. [CrossRef]

57. Chaves, M.M.; Zarrouk, O.; Francisco, R.; Costa, J.M.; Santos, T.; Regalado, A.P.; Rodrigues, M.L.; Lopes, C.M. Grapevine under deficit irrigation: Hints from physiological and molecular data. Ann. Bot. 2010, 105, 661-676. [CrossRef] 